\title{
PRECIPITAÇÃO SAZONAL SOBRE A AMAZÔNIA ORIENTAL NO PERÍODO CHUVOSO: OBSERVAÇÕES E SIMULAÇÕES REGIONAIS COM O REGCM3
}

EVERALDO B. DE SOUZA ${ }^{1}$, MARCIO N.G. LOPES ${ }^{2,1}$, EDSON J.P. DA ROCHA ${ }^{2,1}$, J. RICARDO S. DE SOUZA ${ }^{1}$, ALAN C. DA CUNHA ${ }^{3}$, RENATO R. DA SILVA ${ }^{1}$, DOUGLAS B.S. FERREIRA ${ }^{1}$, DANIEL M. SANTOS ${ }^{1}$, ALEXANDRE M.C. DO CARMO ${ }^{4}$, J. RAIMUNDO A. DE SOUSA ${ }^{5}$, PAULO L. GUIMARÃES $^{6}$, M. AURORA S. DA MOTA ${ }^{1}$, MIDORI MAKINO ${ }^{1}$, RENATO C. SENNA ${ }^{7}$, ADRIANO M.L. SOUSA ${ }^{8}$, GALDINO V. MOTA ${ }^{1}$, PAULO A.F. KUHN ${ }^{1}$, PAULO F. DE S. SOUZA ${ }^{1}$, M. ISABEL VITORINO $^{1}$

${ }^{1}$ Universidade Federal do Pará (UFPA), Faculdade de Meteorologia (FAMET) e Programa de Pós-Graduação em Ciências Ambientais (PPGCA) Belém-PA

${ }^{2}$ Sistema de Proteção da Amazônia, (SIPAM) Belém-PA

${ }^{3}$ Universidade Federal do Amapá,(UNIFAP) Macapá-AP

${ }^{4}$ Faculdade de Oceanografia, (UFPA) Belém-PA

${ }^{5}$ Instituto Nacional de Meteorologia, (INMET) $2^{\circ}$ DISME, Belém-PA

${ }^{6}$ Secretaria de Estado de Meio Ambiente do Pará,(SEMA) Belém-PA

${ }^{7}$ Sistema de Proteção da Amazônia,(SIPAM) CTO-MN, Manaus-AM

${ }^{8}$ Universidade Federal do Rio Grande do Sul, (UFRGS) Porto Alegre-RS

everaldo@ufpa.br

Recebido Março 2008 - Aceito Março 2009

\section{RESUMO}

O presente trabalho apresenta uma contribuição aos estudos de modelagem climática com ênfase na variabilidade pluviométrica sazonal da Amazônia oriental, durante as estações de verão e outono (DJF e MAM). Baseado nos resultados das simulações regionais do RegCM3 para um período de 26 anos (1982/83 a 2007/08) e usando domínio em alta resolução espacial $(30 \mathrm{Km})$ e dois diferentes esquemas de convecção (Grell e MIT), foi investigado o desempenho do modelo em simular a distribuição regional de precipitação sazonal na Amazônia oriental, com referência a um novo conjunto de dados observacional compilado com informações de uma ampla rede integrada de estações pluviométricas. As análises quantitativas evidenciaram que o RegCM3 apresenta erros sistemáticos, sobretudo aqueles relacionados com viés seco no Amapá e norte/nordeste do Pará usando ambos os esquemas Grell e MIT, os quais apontam que o modelo não reproduz as características da ZCIT sobre o Atlântico equatorial. As simulações usando MIT, também apresentaram viés úmido no sudoeste/sul/sudeste do Pará e norte do Tocantins. Além disso, através da técnica de composições, também foi investigado o desempenho do RegCM3 em reproduzir os padrões espaciais anômalos de precipitação sazonal em associação aos episódios ENOS, e as fases do gradiente térmico sobre o Atlântico intertropical. Os resultados demonstraram que o modelo conseguiu representar realisticamente bem o padrão espacial das anomalias pluviométricas acima (abaixo) do normal em grande parte da Amazônia oriental, durante os conhecidos cenários favoráveis, i.e., condições de La Niña e gradiente de aTSM para o Atlântico sul (desfavoráveis, i.e., El Niño e gradiente de aTSM para o Atlântico norte).

Palavras-chave: Precipitação sazonal, Amazônia, simulação climática regional, RegCM3

ABSTRACT: SEASONAL PRECIPITATION IN EASTERN AMAZON DURING RAINY SEASON: REGIONAL OBSERVATIONS AND REGCM3 SIMULATIONS

This paper presents a contribution on the climate modelling studies with emphasis on seasonal rainfall variability in eastern Amazonia, during the austral summer and autumn seasons (DJF and MAM). Based on RegCM3 regional climate simulations for a 26 years period (1982/83 to 2007/08) 
using high resolution domain scale $(30 \mathrm{~km})$ and two different convection schemes (Grell and MIT), it was investigated the model performance to simulate the regional pluviometric distribution in eastern Amazon, with reference to a new observational data base containing regional aspects extracted from a dense rain gauge station network. The quantitative analysis showed that RegCM3 presents systematic errors, especially those related to the dry bias in the Amapá and north/northeast of Pará using both schemes Grell and MIT, which indicate that the model does not reproduce ITCZ characteristics over equatorial Atlantic. The simulations using MIT also indicated wet bias in the southwest/south/southeast of Pará and north of Tocantins. Moreover, through composites technique, it was also investigated RegCM3 response to reproduce the anomalous spatial rainfall patterns in association with ENSO episodes and interhemispheric SSTa gradient phases across the intertropical Atlantic. The results showed that the model represented realistically well the spatial pattern related to the rainfall anomalies above (below) than normal in most of eastern Amazonia, during the known favourable scenarios, i.e., La Niña and south Atlantic SSTa gradient (unfavourable, i.e., El Niño and north Atlantic SSTa gradient).

Keywords: Seasonal precipitation, Amazon, regional climate simulation, RegCM3

\section{INTRODUÇÃO}

A característica intrínseca do clima da Amazônia é a presença de um amplo espectro de variações no tempo e espaço da atividade convectiva tropical e da precipitação, as quais se tornam as variáveis climáticas mais importantes da região.

$O$ foco deste trabalho é na região da Amazônia oriental adjacente à costa Atlântica, onde se observa um máximo pluviométrico ao longo dos Estados do Amapá, Pará e Maranhão, com volume de chuva anual em torno de 2000 a $3000 \mathrm{~mm}$ (Figueroa e Nobre, 1990). A maior parte desta precipitação anual ocorre entre as estações de verão e outono austral (Marengo et al., 2001; De Souza e Ambrizzi, 2003), tipicamente de dezembro a maio, em associação aos padrões de circulação atmosférica quase-estacionários de grande escala associados à Zona de Convergência do Atlântico Sul (ZCAS) e Zona de Convergência Intertropical (ZCIT) (De Souza et al., 2004, De Souza e Rocha, 2006).

No contexto da dinâmica climática tropical, é bem conhecido que a variabilidade interanual e sazonal da estação chuvosa da Amazônia é modulada diretamente pelos padrões oceano-atmosfera de grande escala, associados ao ciclo do El Niño-Oscilação Sul (ENOS) sobre o Oceano Pacífico e as fases do gradiente meridional interhemisférico de anomalias de temperatura da superfície do mar (aTSM) sobre o Oceano Atlântico intertropical (Nobre e Shukla, 1996; De Souza et al., 2000). Através de mudanças significativas nos padrões da circulação troposférica associados às células de Walker e de Hadley (e.g., De Souza e Ambrizzi, 2002; De Souza et al., 2004), ambos os modos climáticos do Pacífico e Atlântico interferem na posição e intensidade das bandas de nebulosidade convectiva da ZCAS e ZCIT e, portanto, modulam a distribuição de chuva na região. As análises observacionais conduzidas por De Souza et al. (2005), considerando dois cenários climáticos contrastantes denominados de favorável: concomitância de condições de La
Niña e gradiente meridional de aTSM apontando para a bacia do Atlântico sul (desfavorável: concomitância de condições de El Niño e gradiente meridional de aTSM apontando para a bacia do Atlântico norte), evidenciaram a predominância de circulação atmosférica ascendente (descendente) nas regiões da célula de Walker/Hadley equatorial, que fortaleceu (inibiu) a ZCIT e consequentemente resultou em precipitação sazonal significativamente abundante (deficitária) no leste da Amazônia.

Diversas atividades do setor produtivo (particularmente aquelas ligadas à agricultura, geração e distribuição de energia hidroelétrica, indústria, etc) são dependentes da variabilidade pluviométrica regional, em especial nas regiões situadas nos trópicos (como é o caso da Amazônia), tornando a população vulnerável ao comportamento e variabilidade do sistema climático. Portanto, estudos que visam o entendimento científico das causas e conseqüências da variabilidade de chuva, e uma ferramenta que possa prevê-la, são imprescindíveis para gerar informações e produtos climatológicos úteis ao benefício da sociedade. Nesse sentido, os modelos climáticos globais e regionais são reconhecidamente ferramentas chave, uma vez que os mesmos conseguem equacionar com boa aproximação o sistema climático e assim, investigar vários detalhes dos mecanismos ou processos reguladores do clima e sua variabilidade espaço-temporal.

Estudos anteriores que abordaram o uso de modelagem climática sobre a América do Sul, enfatizaram os aspectos da circulação atmosférica e variabilidade da precipitação em escala global e regional (Nobre et al., 2001; Cavalcanti et al., 2002; Druyan et al., 2002; Chou et al., 2002; Misra et al., 2003; Rojas e Seth, 2003). Misra et al. (2003) investigaram os aspectos da previsão sazonal de precipitação para o verão sobre a América do Sul, com base em modelo global e regional, obtendo melhores simulações quando da utilização de média de conjunto do modelo regional, especialmente na região de atuação da ZCAS. 
Mais recentemente, vários trabalhos avaliaram o desempenho de modelos regionais em simular o clima regional de dados retrospectivos para algumas regiões específicas. Cuadra e Rocha (2006) usaram simulações com o modelo RegCM3, considerando a resolução de $50 \mathrm{~km}$ em duas situações de verão (1990 e 1998). Os mesmos obtiveram resultados da precipitação simulada para a região sudeste do Brasil bastante consistente com as observações do NCDC (National Climatic Data Center), tanto em termos de média e anomalia sazonal, como em termos das variações intrasazonais. Sun et al. (2006) aplicaram downscaling sazonal para a região do Nordeste do Brasil, usando o modelo regional RSM (modelo espectral do NCEP) com resolução de $60 \mathrm{Km}$ aninhado ao modelo global ECHAM4.5. Simulações climatológicas sazonais de 30 anos (1971-2000), validadas com dados de precipitação de 95 estações pluviométricas, demonstraram que o RSM consegue resolver aspectos regionais do regime chuvoso sazonal do Nordeste, porém apresenta viés seco sistemático, o qual concorda com os resultados de Nobre et al. (2001). Fernandez et al. (2006) usaram dois modelos climáticos regionais, o ETACLIM e o RegCM3, ambos com resolução de $80 \mathrm{~km}$ numa integração para 10 verões (1991 a 2000). Validações da chuva simulada com os dados do Global Precipitation Climatology Project (GPCP), revelaram que a performance dos dois modelos varia regionalmente, mas não foram detectadas mudanças muito significativas de um modelo para o outro. Em geral, o ETACLIM e o RegCM3 apresenta um viés negativo em grande parte da América do Sul, especialmente para a região central da Amazônia. Seth et al. (2007) examinaram integrações climatológicas (1982-2003) de precipitação geradas pelo RegCM3 numa resolução de $80 \mathrm{Km}$, e concluíram, que o ciclo semi-anual é bem simulado, mas durante o verão sobre a Amazônia nota-se um viés seco com referência aos dados de chuva do CMAP - Climate Prediction Center Merged Analysis of Precipitation. Esses resultados foram consistentes com os obtidos por Seth e Rojas (2003) usando o RegCM2.

No contexto dos estudos de modelagem regional supracitados, há um consenso de que os processos ou mecanismos dinâmicos da circulação atmosférica são bem representados nas simulações. Porém, a maioria desses estudos abordaram análises sazonais e resolução espacial variando de 50 a $80 \mathrm{Km}$, sendo que as validações de precipitação sazonal são enfatizadas para as regiões sudeste e nordeste do Brasil. Assim sendo, o presente trabalho apresenta uma contribuição aos estudos de modelagem climática específica para a região da Amazônia oriental, através de simulações climatológicas usando o modelo RegCM3 para um período de 26 anos (1982/83 a 2007/08), em uma grade com alta resolução espacial (30 $\mathrm{Km}$ ). Análises de validação ou desempenho da precipitação climatológica simulada serão realizadas de forma qualitativa e quantitativa com referência a um recente conjunto de dados observacional, que contém aspectos regionais extraídos de informações provenientes de uma ampla rede integrada de estações pluviométricas da Amazônia oriental. Portanto, o objetivo do presente trabalho é documentar os aspectos regionais da precipitação sazonal sobre a Amazônia oriental, bem como avaliar a performance do modelo climático regional $\mathrm{RegCM} 3 \mathrm{em}$ capturar essa distribuição pluviométrica regional. Além disso, investigam-se os padrões anômalos regionais de precipitação sazonal observada e simulada, durante cenários climáticos de grande escala relacionados aos eventos ENOS e as fases do gradiente de aTSM sobre o Atlântico intertropical.

\section{DADOS E METODOLOGIA}

\subsection{Nova base de dados observacional de precipitação regional}

Com o objetivo de avaliar os resultados das simulações geradas pelo RegCM3, utiliza-se a base de dados observacional do projeto RPCH - Rede Estadual de Previsão Climática e Hidrometeorológica do Pará (De Souza et al., 2007), que consiste em um novo conjunto de dados integrados contendo o máximo possível de medições de precipitação, registradas pelas estações meteorológicas espalhadas sobre a Amazônia oriental. Procedimentos de controle de qualidade são aplicados para checar e verificar a presença de dados errados ou faltantes, sendo que foram selecionadas apenas as estações contendo menos do que $5 \%$ de dados faltantes. Essas eventuais falhas foram preenchidas por interpolação de dados das estações vizinhas. Ao final foram selecionadas 150 estações pluviométricas, com observações mensais ininterruptas entre 1978 e 2008, cujas localizações encontram-se na Figura 1a. Ressalta-se que algumas áreas do noroeste e sul do Pará, onde há topografia relativamente acentuada, condições de difícil acesso e/ou com reservas indígenas, a densidade de estações é mais baixa. A fim de obter um conjunto de dados de precipitação regional em pontos de grade no domínio da Amazônia oriental, foi empregada a interpolação espacial (utilizando o método do inverso das distâncias ao quadrado, e.g. De Souza et al., 2004; 2005) dos dados de estações para uma grade regular com resolução de $0.27^{\circ} \times 0.27^{\circ}$ de latitude e longitude (na escala do modelo RegCM3). Este novo conjunto de dados foi denominado de precipitação RPCH, o qual foi também comparado com outras bases de dados de precipitação, a saber: o GPCP (Adler et al., 2003) e o CPC-NCEP (Silva et al., 2007) que possuem resoluções aproximadas de $270 \mathrm{Km}$ e $110 \mathrm{Km}$, respectivamente. Comparando-se a climatologia (média 1978-2007) anual da precipitação do GPCP (Figura 1b) e do CPC (Figura 1c) com a precipitação regional da RPCH (Figura 1d), evidencia-se uma ótima consistência espacial entre as diferentes bases de dados. 
Não obstante, a precipitação RPCH captura alguns aspectos regionais intrínsecos da alta variabilidade espaço-temporal da pluviometria tropical, tais como, a representação de dois máximos no oeste do Pará (Santarém), a separação dos dois máximos na foz do rio Amazonas entre o sul do Amapá e o nordeste do Pará, os quais se encontram ausentes ou bastante suavizados pelo GPCP e CPC (De Souza et al., 2007).

\subsection{Descrição do RegCM3 e configuração das simulações}

Utiliza-se a última versão do Regional Climate Model version 3 (RegCM3), distribuída pelo International Centre for Theoretical Physics (ITCP). O RegCM3 é a terceira geração de um modelo numérico climático regional, originalmente desenvolvido no NCAR (Giorgi e Bates, 1989; Dickinson et al., 1989) - o RegCM1, o qual foi sistematicamente aprimorado por Giorgi et al. (1993a, 1993b) - o RegCM2, e Giorgi e Mearns (1999) - o RegCM2.5. Atualmente, o ITCP RegCM3 é um modelo de área limitada, em coordenada vertical sigma e grade horizontal de Arakawa-Lamb B, com as equações primitivas para um fluído compressível e hidrostático (Pal et al., 2007). O RegCM3 usa o esquema de superfície Biosphere-Atmosphere Transfer Scheme (Dickinson et al. 1993) para resolver, em cada ponto da grade, os processos de interação da superfície (tipos de vegetação e solo) com a atmosfera, levando-se em consideração os processos de trocas turbulentas de momentum, energia e vapor de água. $\mathrm{O}$ transporte turbulento dessas quantidades são resolvidos com as correções propostas por Holtslag et al. (1990). Para a transferência radiativa, utiliza-se o esquema do Community Climate Model 3 (Kiehl et al., 1996), no qual as taxas de aquecimento e fluxos na superfície para a radiação de ondas curtas e ondas longas sob condições de céu claro e nublado são calculadas separadamente. Os cálculos de transferência radiativa consideram os efeitos dos gases $\mathrm{CO} 2, \mathrm{H} 2 \mathrm{O}$ e $\mathrm{O} 3$ no infravermelho e dos gases $\mathrm{CO} 2, \mathrm{H} 2 \mathrm{O}, \mathrm{O} 3 \mathrm{e} \mathrm{O} 2$ para radiação solar. O esquema inclui também os efeitos dos gases de efeito estufa (NO2, CH4 , CFCs), aerossóis atmosféricos e água de nuvem. Neste trabalho, utilizam-se dois tipos de esquemas de parametrização convectiva. O esquema Grell (Grell, 1993) de fluxo de massa, que inclui os efeitos de umedecimento e aquecimento de correntes ascendentes e descendentes. Devido à simplicidade do esquema, torna-se necessário adotar um fechamento para completá-lo, de maneira que o esquema Grell estima as propriedades da convecção e o fechamento, e especifica a quantidade da convecção que ocorre, de forma a encontrar a taxa de estabilização desejada. Aqui, utiliza-se o fechamento Fritsch-Chappell, no qual a energia de flutuabilidade ocorre numa escala de tempo de 30 minutos. O outro esquema é o MIT - Massachusetts Institute of Technology (Emanuel e Zivkovic-Rothman, 1999), recentemente implementado no RegCM3, no qual a convecção é disparada quando o nível flutuante neutro é maior que o nível de condensação por levantamento (base da nuvem). $\mathrm{O}$ ar ascende entre estes dois níveis e uma fração da mistura condensada forma precipitação enquanto a outra forma nuvem, sendo que a nuvem mistura-se (o)

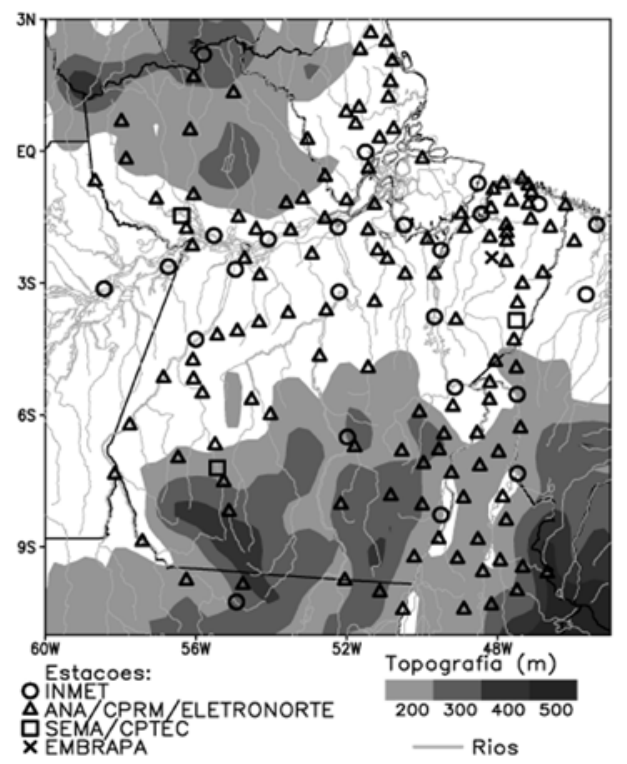

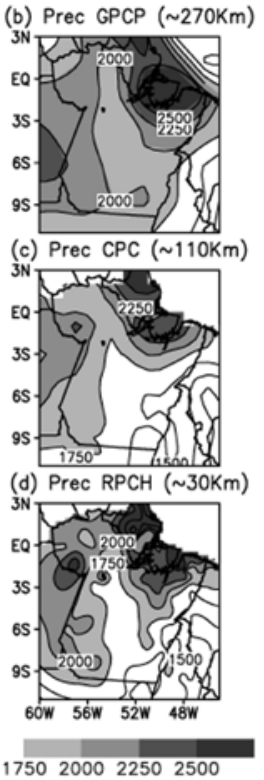

Figura 1 - (a) Localização das estações pluviométricas (símbolos) sobre a Amazônia oriental usadas para gerar a precipitação RPCH, com mapa de fundo mostrando a topografia acima de $200 \mathrm{~m}$ e rede de drenagem (rios); Precipitação (mm) climatológica anual (média 1978-2007) correspondente a base de dados do (b) GPCP, (c) CPC e (d) RPCH. 
com o ar ambiente de acordo com um espectro uniforme que ascende ou descende a parcela para o nível neutro. As taxas de entranhamento e desentranhamento são funções dos gradientes verticais de flutuação nas nuvens. O RegCM3 também dispõe do SUB-grid EXplicit moisture scheme (SUBEX) (Pal et al., 2000) para representar a precipitação de grande escala resolvida pelo modelo. O SUBEX considera a variabilidade das nuvens na escala de subgrade e inclui formulações para a autoconversão de água de nuvem em água de chuva.

No presente trabalho, a dimensão da grade do RegCM3 configurada para a região da Amazônia oriental, foi de $118 \mathrm{x}$ 78 pontos em latitude $x$ longitude, com resolução horizontal de $0,27^{\circ} \times 0,27^{\circ}(30 \mathrm{Km})$, centrado em $2^{\circ} \mathrm{S} / 49^{\circ} \mathrm{W}$ com 18 níveis na vertical (sendo 7 níveis abaixo de $800 \mathrm{hPa}$ ) e usando projeção mercator normal. Foram realizadas 26 simulações sazonais usando os esquemas Grell e MIT para o período de 1982/83 a $2007 / 08$. Uma vez que o foco deste trabalho é o período chuvoso da Amazônia, as simulações foram iniciadas em 01 de novembro e finalizadas em 31 de maio do ano seguinte, considerando o tempo de spin-up o primeiro mês da integração. As rodadas foram atualizadas (updated) a cada 6 horas com as condições iniciais e de contorno da reanálise NCEP/NCAR (Kaynal et al., 1996), e usando os dados mensais observados de TSM de Reynolds et al. (2002).

\subsection{Métodos de análise}

As análises de desempenho das simulações climatológicas de 26 anos (1982/83-2007/08) geradas pelo RegCM3, são realizadas com referência aos dados observacionais da precipitação RPCH, de maneira que as simulações e observações encontram-se dispostos no mesmo domínio espacial $(30 \mathrm{Km})$. As comparações objetivas entre a precipitação simulada e observada baseiam-se no cálculo do viés $(\mathrm{B})$ dado pela expressão $\mathrm{B}=\left(\mathrm{P}_{\mathrm{I}, \mathrm{j}}-\mathrm{O}_{\mathrm{I}, \mathrm{j}}\right) / \mathrm{n}$ que expressa a média da diferença entre a precipitação prevista $(\mathrm{P})$ e a observada $(\mathrm{O})$ para cada ponto de grade de coordenada $i, j$, sendo $n=26$, i.e., o número de estações de DJF e MAM no período de 1982/83 a 2007/08. B fornece a indicação de superestimativa ou subestimativa do modelo, sendo que valores próximos de zero representam os menores erros sistemáticos.

Foi calculado também o Erro Médio Absoluto (EMA) dado pela expressão EMA $=\frac{1}{n} \Sigma\left|P_{i, j}-O_{i, j}\right|$, que é menos sensível a grandes desvios que se afastam da média, sendo considerada uma robusta medida de desempenho (Sun et al., 2006).

Calculou-se também, a correlação (CA) entre as anomalias de precipitação observada e simulada em cada ponto de grade do período de 26 anos, usando a expressão

$$
\mathrm{CA}=\frac{\sum_{1}^{n}\left\lfloor\left(p_{i, j}-\bar{p}_{i, j}\right)-\left(o_{i, j}-\bar{o}_{i, j}\right)\right]}{\left[\sum_{1}^{n}\left(p_{i, j}-\bar{p}_{i, j}\right)^{2} \sum_{1}^{n}\left(o_{i, j}-\bar{o}_{i, j}\right)^{2}\right]^{1 / 2}}
$$

sendo $\bar{P}$ e $\bar{O}$ os valores climatológicos (média dos 26 anos) previsto e observado, respectivamente.

Utilizou-se também, a técnica de composições das anomalias de precipitação regional observada pela RPCH e simulada pelo RegCM3 para os anos com registro das fases do ENOS sobre o Pacífico (quatro episódios El Niño: 1982/83, 1986/87, 1991/92 e 1997/98; sete episódios La Niña: 1983/84, 1984/85, 1985/86, 1988/89, 1995/96, 1998/99 e 1999/00) e das fases do gradiente de aTSM no Atlântico intertropical (cinco episódios com o gradiente para o Atlântico Norte: 1982/83, 1991/92, 1996/97, 2001/02 e 2006/07; quatro episódios com o gradiente para o Atlântico Sul: 1984/85, 1985/86, 1988/89 e 1993/94). Tais eventos foram selecionados objetivamente, com base nos critérios de Trenberth (1997) e De Souza et al. (2005). Para o cômputo das anomalias de precipitação observada e simulada, usa-se a respectiva climatologia de 26 anos (1982/832007/08) da RPCH e do RegCM3.

\section{RESULTADOS}

\subsection{Precipitação climatológica observada e simulada (DJF e MAM)}

Nesta secção, analisam-se os resultados da precipitação climatológica observada e simulada sobre a Amazônia oriental, correspondentes a média do período de 26 anos (1982/83 a 2007/08).

A Figura 2 mostra os mapas climatológicos sazonais da precipitação observada pela RPCH, e da precipitação simulada usando os esquemas de convecção Grell (RegCM3/Grell) e MIT (RegCM3/MIT) para o período do verão - DJF e outono - MAM. Analisando a precipitação observada durante o trimestre DJF (Figura 2a), evidencia-se um máximo pluviométrico, com valores sazonais de 700 a $900 \mathrm{~mm}$, englobando os setores oeste e sudoeste do Pará e centro-sul do Tocantins. Este máximo é primariamente associado à manifestação da ZCAS (De Souza e Ambrizzi, 2003), que apresenta freqüência máxima de ocorrência nos meses de dezembro e janeiro (Carvalho et al., 2004). Ainda no verão, observa-se outro máximo de precipitação situado na faixa litorânea do Amapá e Pará, incluindo a ilha de Marajó, com valores acima de $1000 \mathrm{~mm}$. Este máximo na faixa litorânea é devido à influência da ZCIT, cuja posição central da banda de nebulosidade tropical posiciona-se em latitudes equatoriais nestes meses (De Souza et al., 2004). Durante o trimestre MAM (Figura 2b), ocorre uma diminuição significativa da precipitação na parte sul/sudeste da Amazônia oriental, devido o retraimento dos episódios da ZCAS ou de sistemas frontais (De Souza e Ambrizzi, 2003). Em compensação, deflagra-se a intensificação e generalização do máximo pluviométrico sazonal na porção setentrional da Amazônia, com destaque 
para o máximo entre 900 e 1000 mm no oeste do Pará (região de Santarém) e principalmente o máximo entre 1000 e 1400 mm ocorrendo na maior parte do Amapá e nordeste do Pará. Essa intensificação da precipitação deve-se a atuação direta da ZCIT atingindo sua posição climatológica mais austral em março (Nobre e Shukla, 1996; De Souza e Nobre, 1998), sendo, portanto, o principal sistema meteorológico indutor de chuva na Amazônia, durante o pico da estação chuvosa (De Souza e Rocha, 2006). Em termos qualitativos, a comparação visual entre os valores de chuva observada e simulada pelo RegCM3, para ambas as estações de DJF e MAM, demonstra que algumas regiões apresentam discrepâncias para mais e para menos nos valores de precipitação prevista, notadamente nas regiões situadas ao norte/nordeste (fronteira do Amapá e Pará) para a precipitação RegCM3/Grell (Figuras 2c e 2d), e também nas áreas localizadas ao sudoeste/sul/sudeste do Pará e norte do Tocantins para a precipitação RegCM3/MIT (Figuras 2e e 2f). Apesar das diferenças no volume de chuva, ressalta-se que o padrão espacial dos máximos e míninos climatológicos, em ambos os períodos do verão e outono, são razoavelmente capturados nas simulações do modelo regional.

Considerando as análises pontuais, estimadas através das médias espaciais obtidas em áreas-chave que incluem boa densidade de estações pluviométricas (Figura 3), observa-se que o RegCM3, embora apresente chuva subestimada, consegue capturar a evolução da chuva sazonal intensificando-se de DJF para MAM, nas porções localizadas a oeste, noroeste, norte, nordeste e centro do Pará. Nestes pontos, as simulações do esquema MIT se aproximam mais das observações, quando comparado com o esquema Grell, notadamente no noroeste. Verifica-se a pior subestimativa no nordeste e norte e uma melhora sensível no oeste e centro do Pará. No sudoeste e leste, ressalta-se o valor simulado muito próximo do observado em MAM. Nos pontos situados a leste e sudeste, o modelo contrariou a diminuição relativa da chuva sazonal de DJF para MAM. (a) RPCH DJF

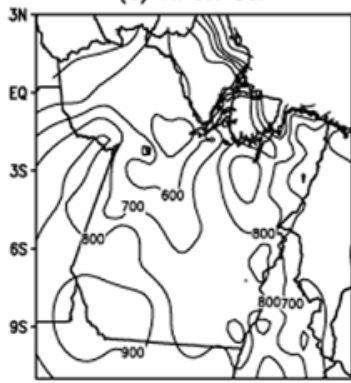

(c) RegCM3/Grell DJF

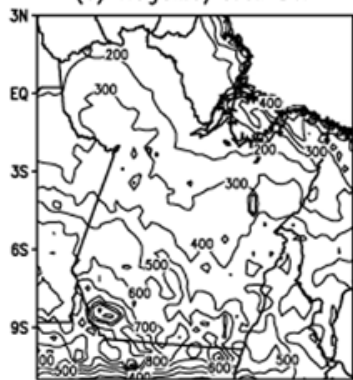

(e) RegCM3/MIT DJF

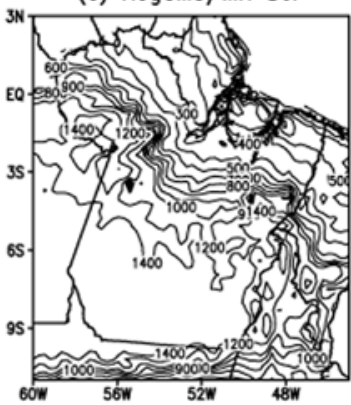

(b) RPCH MAM

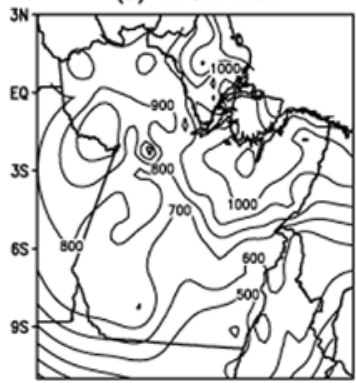

(d) RegCM3/Grell MAM

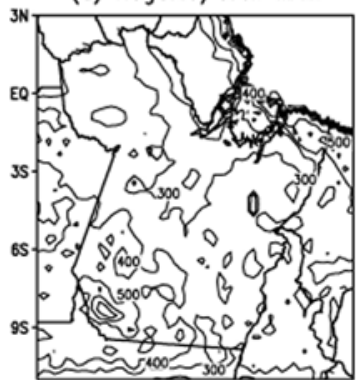

(f) $\mathrm{RegCM} 3 / \mathrm{MIT}$ MAM

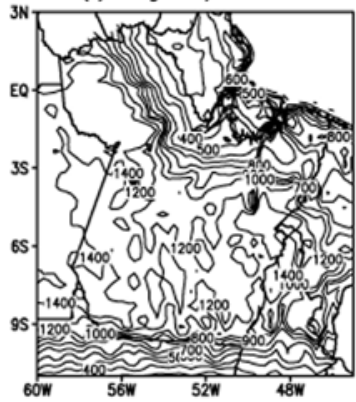

Figura 2 - Precipitação (mm) climatológica sazonal observada pela RPCH para (a) DJF e (b) MAM; e precipitação (mm) simulada pelo RegCM3 usando o esquema Grell para (c) DJF e (d) MAM e usando o esquema MIT para (e) DJF e (f) MAM. 
A análise mais detalhada, em termos quantitativos, da performance do RegCM3 em simular a distribuição regional da precipitação sazonal, com referência a precipitação observada pela RPCH, é feita com base no viés e erro médio absoluto (EMA), os quais foram calculados para cada ponto de grade da Amazônia oriental.

A precipitação simulada usando a parametrização Grell, apresenta predominância de valores subestimados, ou seja, viés seco (valores negativos), principalmente na porção nordeste da Amazônia oriental (grande parte do Amapá e nordeste do Pará incluindo a ilha de Marajó) no período de DJF (Figura 4a), sendo que essa subestimativa é maior na estação de MAM (Figura 4b). Não obstante, as áreas situadas no noroeste e sul do Pará, e também no extremo norte do Tocantins, são as regiões onde a precipitação RegCM3/Grell apresenta os melhores resultados simulados (regiões em branco com viés entre -10 e 10) para DJF. O sul/sudeste do Pará e grande parte do Tocantins são as áreas onde a precipitação RegCM3/Grell apresenta melhor desempenho no período de MAM. Por outro lado, a precipitação modelada utilizando o esquema de convecção MIT exibe alternância de valores superestimados (viés úmido, valores positivos), notadamente na porção oeste, sudoeste, sul e sudeste do Pará/norte do Tocantins, e de valores subestimados (viés seco, valores negativos) especialmente no Amapá/nordeste do Pará, durante ambas as estações de DJF e MAM (Figuras $4 \mathrm{c}$ e $4 \mathrm{~d})$. Na porção sul do Pará, o viés úmido é maior em DJF, quando comparado a MAM. Inversamente, na faixa litorânea do Amapá e Pará o viés seco é maior em MAM, quando comparado a DJF. Analisando as regiões em que tem-se viés entre -10 e 10 (áreas brancas), particularmente numa faixa que vai do noroeste, passa pelo centro (englobando parte dos municípios de Altamira, Tucurui e Paragominas), até parte do nordeste paraense (a leste da região metropolitana de Belém), a precipitação simulada pelo RegCM3 apresenta melhor desempenho.

A Figura 5 mostra os mapas espaciais do EMA, sendo que os maiores valores indicam a ocorrência de erros sistemáticos do modelo relacionados a superestimativa/subestimativa discutida anteriormente. Em ambas as estações de DJF e MAM, evidencia-se que os resultados da precipitação modelada pelo RegCM3/Grell, apresentam erros mais significativos sobre a região norte/nordeste, notadamente no Amapá e nordeste do Pará incluindo a ilha de Marajó (Figuras 5a e 5b). Por outro lado, os erros da precipitação simulada pelo RegCM3/MIT configuram-se espacialmente na maior parte da Amazônia oriental, principalmente no norte de Tocantins e oeste/sul/ sudoeste/sudeste do Pará, e também no centro-sul do Amapá e norte/nordeste do Pará (Figuras $5 \mathrm{c}$ e $5 \mathrm{~d}$ ).

Diante dos resultados supracitados, verifica-se claramente que o modelo apresenta falhas na representação do máximo pluviométrico associado à ZCIT Atlântica. Para uma análise mais detalhada desta região, comparam-se os valores simulados com a precipitação observada pelo GPCP, que contempla dados de satélites sobre o oceano e de informações de estações sobre o continente. Em DJF, o GPCP indica o posicionamento climatológico da banda zonal de precipitação associada à ZCIT alongada sobre o Atlântico equatorial na região entre $2^{\circ} \mathrm{N}-4^{\circ} \mathrm{N}$,
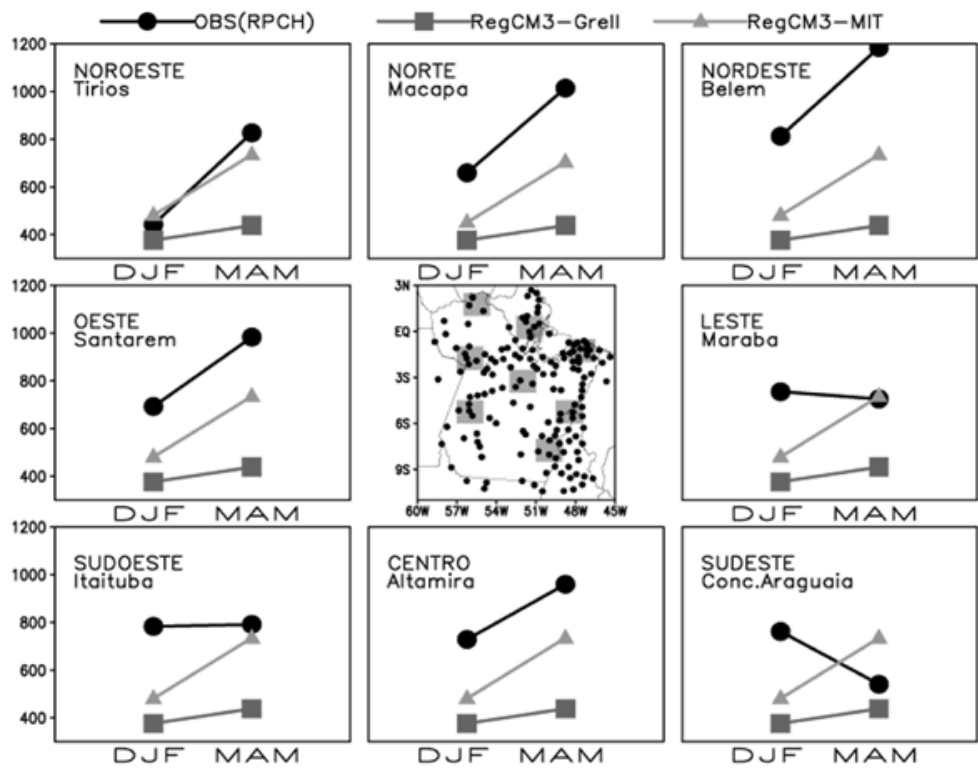

Figura 3 - Precipitação $(\mathrm{mm})$ pontual observada $(\mathrm{RPCH})$ e simulada (RegCM3) em áreas-chave situadas no noroeste, norte, nordeste, oeste, leste, sudoeste, centro e sudeste do Pará para as estações de DJF e MAM. Os quadrados cinza no mapa central indicam a localização de cada área onde foi obtida a média espacial com o respectivo nome do município de referência regional. 
sendo que no continente observa-se o máximo englobando a ilha de Marajó, nordeste do Pará e litoral do Amapá (Figura 6a). Subsequentemente, a ZCIT migra para o Atlântico equatorial sul em MAM, deflagrando o máximo pluviométrico de outono em grande parte da Amazônia oriental e norte do Nordeste Brasileiro (Figura 6b). O modelo RegCM3 para ambos os esquemas de convecção, em geral, não conseguiu reproduzir a configuração espacial da chuva associada à ZCIT, principalmente sobre a região oceânica. Em DJF, verifica-se sobre o Atlântico equatorial em torno de $2^{\circ} \mathrm{N}-4^{\circ} \mathrm{N}$, consistente com a posição do GPCP, uma região contendo valores de $3 \mathrm{~mm}$ no RegCM3/Grell e de $1 \mathrm{~mm}$ no RegCM3/MIT (Figuras 6c e 6e). Em MAM, a precipitação simulada no oceano realmente não reproduz o padrão observado (Figuras 6d e 6f). Entretanto, sobre a região continental da Amazônia oriental, os resultados das simulações, embora com valores subestimados, são consistentes com o padrão observado. Em DJF, a precipitação prevista pelo Grell indica máximos restritos na faixa litorânea desde o Amapá até o Ceará (Figura 6c), enquanto que no esquema MIT tais máximos configuram-se mais adentro do continente (Figura 6e), se aproximando mais do padrão observado pelo GPCP. Na estação seguinte, MAM, o modelo mostra a intensificação da precipitação ao longo da faixa norte-nordeste do Brasil, entre o Amapá e o Ceará, com valores subestimados no esquema Grell e mais próximos do GPCP no esquema MIT (Figuras 6d e 6f). (a) RegCM3/Grell DJF

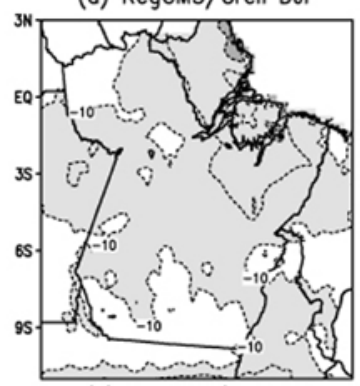

(c) RegCM3/MIT DJF

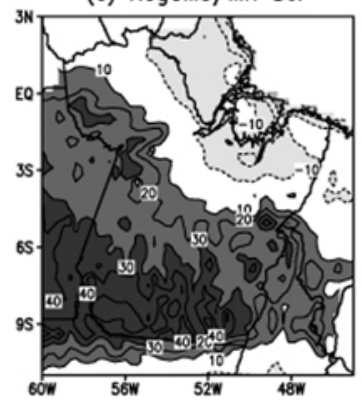

(b) RegCM3/Grell MAM

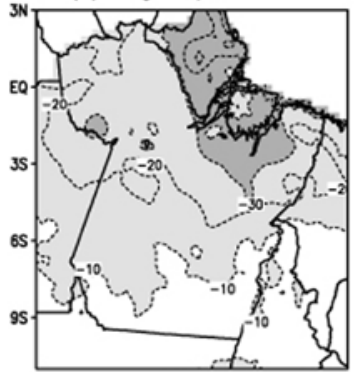

(d) RegCM3/MIT MAM

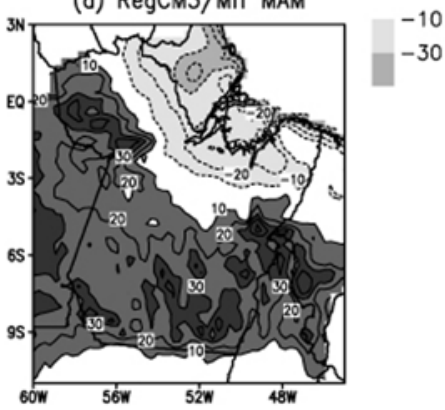

Figura 4 - Viés da precipitação simulada pelo RegCM3 usando o esquema Grell para (a) DJF e (b) MAM e usando o esquema MIT para (c) DJF e (d) MAM. A escala de cores indica os valores em mm.

\subsection{Correlações entre anomalias de precipitação observada e simulada}

A análise quantitativa das simulações climatológicas em termos do sinal das anomalias de precipitação é avaliada através da correlação de anomalias (CA), mostrada na Figura 7. Em geral, notam-se correlações positivas na maior parte da Amazônia oriental para ambas as estações de DJF e MAM, e para ambos os esquemas de conveç̧ão. Isso indica que o sinal das anomalias de precipitação simulada acompanha o mesmo sinal das anomalias de precipitação observada. Considerando as simulações usando Grell, notam-se correlações positivas significantes principalmente nos setores oeste, centro, norte e nordeste da região (Figuras 7a e 7b). As previsões utilizando MIT mostram correlações positivas generalizadas sobre toda região, com exceção de pequenas áreas do sul e sudeste do Pará (Figuras 7c e 7d).

\subsection{Composições das anomalias de precipitação modulada pelo Pacífico/Atlântico}

Nesta secção, apresentam-se os resultados das composições das anomalias de precipitação observada e simulada correspondentes aos episódios ENOS no Pacífico e fases do gradiente de aTSM no Atlântico intertropical. (a) RegCM3/Grell DJF

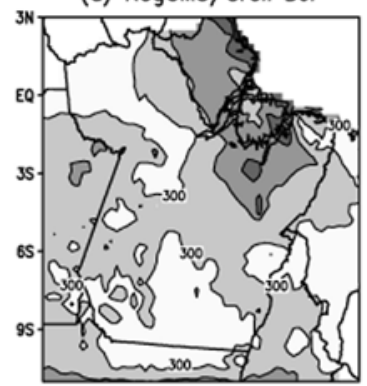

(c) RegCM3/MIT DJF

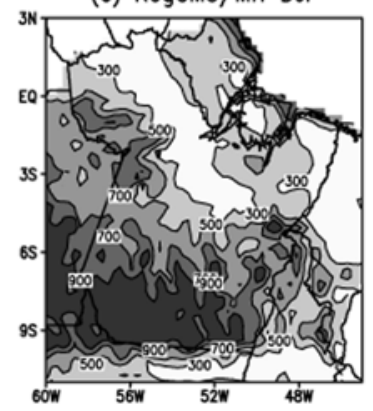

(b) RegCM3/Grell MAM

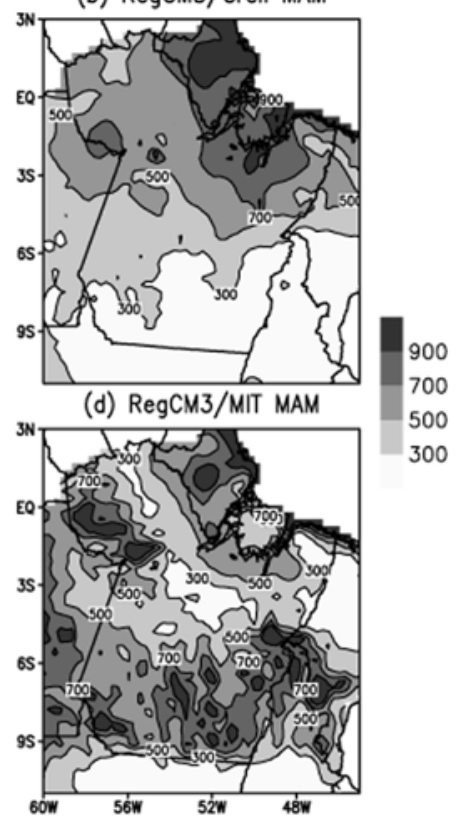

Figura 5 - Erro médio absoluto (EMA) da precipitação simulada pelo RegCM3 usando o esquema Grell para (a) DJF e (b) MAM e usando o esquema MIT para (c) DJF e (d) MAM. A escala de cores indica os valores em mm. 


\subsubsection{Cenários favoráveis (La Niña no Pacífico e Gradiente de aTSM para o Atlântico Sul)}

Nas Figuras 8a e 8b, nota-se a característica típica dos eventos La Niña, com a predominância de aTSM negativas englobando a maior parte do Oceano Pacífico tropical, durante DJF e MAM. Sabe-se que o impacto da La Niña é favorável à ocorrência de chuva acima do normal na Amazônia induzida pela ZCIT (De Souza et al., 2000) devido à intensificação do ramo ascendente da célula de Walker sobre a troposfera equatorial da América do Sul (Ambrizzi et al., 2004; De Souza et al., 2005). De fato, os dados observacionais evidenciam o predomínio de anomalias positivas de precipitação nos setores oeste, noroeste e nordeste do Pará durante DJF (Figura 8c), sendo que tais anomalias positivas se estendem para o sudoeste, centro, norte e leste do Pará durante MAM (Figura 8d). A resposta do modelo RegCM3 em simular a distribuição anômala de chuva regional sobre a Amazônia oriental, durante os anos de La Niña, mostra-se consistente na indicação de chuva acima do normal em grande parte da Amazônia oriental. Embora se perceba a superestimativa no sinal das anomalias previstas sobre o setor sul/sudeste da região, as simulações usando Grell captam muito bem o padrão espacial daquelas anomalias positivas de precipitação observada em DJF e MAM, sendo que o modelo também consegue representar adequadamente o deslocamento das anomalias positivas para o setor norte, nordeste e leste da região de DJF para MAM (Figuras 8e e 8f). Por outro lado, (a) GPCP DJF

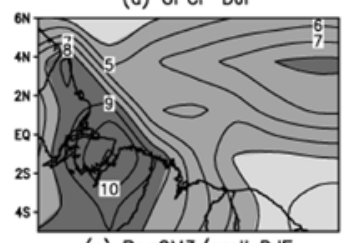

(c) RegCM3/grell DJF

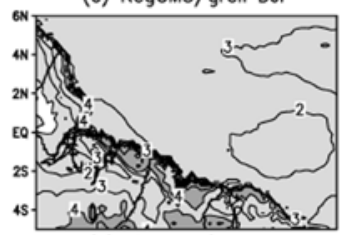

(e) RegCM3/MIT DJF

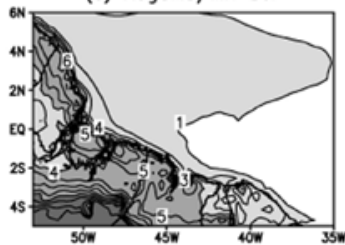

(b) GPCP MAM

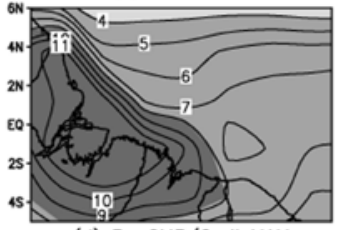

(d) RegCM3/Grell MAM

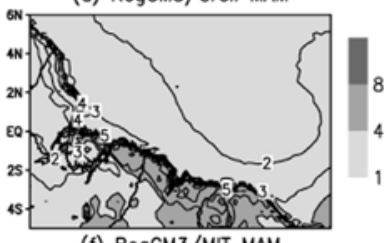

(f) $\mathrm{RegCM} 3 /$ MIT MAM

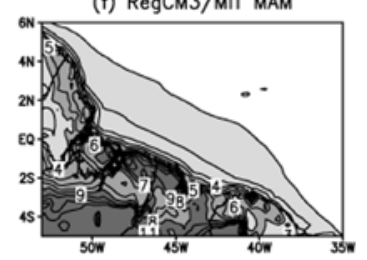

Figura 6 - Precipitação $(\mathrm{mm})$ climatológica sazonal observada pelo GPCP para (a) DJF e (b) MAM, precipitação simulada pelo RegCM3 usando o esquema Grell para (c) DJF e (d) MAM e usando o esquema MIT para (e) DJF e (f) MAM. usando o esquema MIT também nota-se que o modelo captura a distribuição espacial das anomalias positivas de precipitação, porém os valores encontram-se excessivamente altos em ambas as estações de DJF e MAM, principalmente nos setores oeste, sudoeste e leste da região (Figuras $8 \mathrm{~g}$ e $8 \mathrm{~h}$ ).

A Figuras $9 \mathrm{a}$ e $9 \mathrm{~b}$ mostram as condições térmicas associadas à fase do gradiente de aTSM apontando para a bacia do Atlântico Sul, com a manifestação simultânea de anomalias negativas/positivas sobre a bacia norte/sul do Oceano Atlântico tropical durante DJF e MAM. Tais condições associam-se ao posicionamento da ZCIT ao sul do equador no Atlântico intertropical (Nobre e Shukla, 1996; De Souza et al., 1998), que resulta numa estação chuvosa pluviometricamente abundante na Amazônia oriental (De Souza et al., 2004). O sinal da precipitação regional observada pela RPCH indica, de fato, a presença de anomalias positivas de precipitação espacialmente generalizadas sobre a Amazônia oriental durante DJF (Figura 9c) e restritas aos setores central, leste e nordeste da região durante MAM (Figura 9d). Os resultados da precipitação simulada pelo modelo RegCM3, durante tais condições favoráveis no Atlântico, mostram-se consistentes aos dados observacionais. Verifica-se o predomínio de anomalias positivas de precipitação englobando grande parte da Amazônia oriental, sendo que o (a) RegCM3/Grell DJF

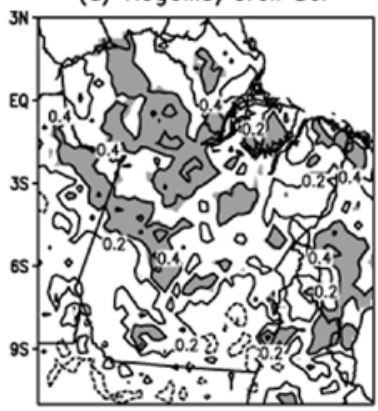

(c) RegCM3/MIT DJF

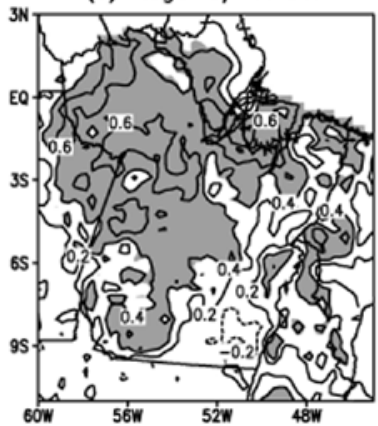

(b) RegCM3/Grell MAM

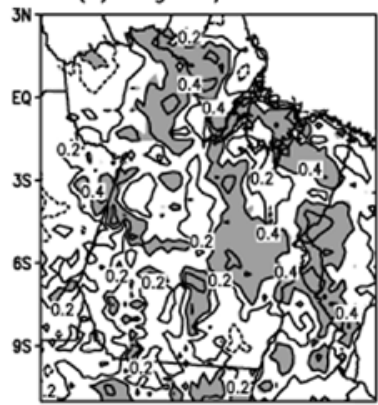

(d) RegCM3/MIT MAM

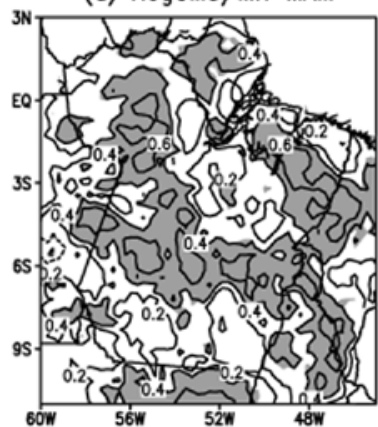

Figura 7 - Correlações entre as anomalias de precipitação RPCH e as anomalias de precipitação simulada pelo RegCM3 usando o esquema de Grell para (a) DJF e (b) MAM e usando o esquema MIT para (c) DJF e (d) MAM. Isolinhas contínuas/pontilhadas indicam correlações positivas/negativas, sendo que as áreas em cinza indicam correlações significantes ao nível de 95\% segundo test-T de Student. 
padrão espacial das anomalias de chuva é mais bem representado usando o esquema Grell em DJF e principalmente em MAM (Figuras 9e e 9f), enquanto que o esquema MIT, embora também mostre boa representação espacial das anomalias positivas, indica valores superestimados na porção oeste, sul e sudeste da região (Figuras $9 \mathrm{~g} \mathrm{e} 9 \mathrm{~h}$ ). Novamente, ressalta-se que o esquema Grell simulou adequadamente o deslocamento para leste das anomalias pluviométricas evoluindo de DJF para MAM.

\subsubsection{Cenários desfavoráveis (El Niño no Pacífico e Gradiente de aTSM para o Atlântico Norte)}

As Figuras 10a e 10b mostram as condições associadas aos episódios El Niño, ou seja, aquecimento anômalo das (a) aTSM DJF

(c) RPCH DJF

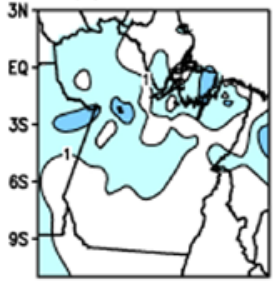

(e) RegCM3/Grell DJF

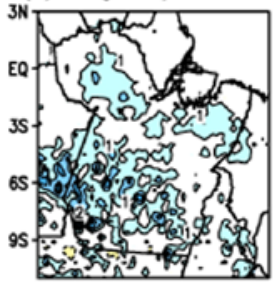

(g) RegCM3/MIT DJF

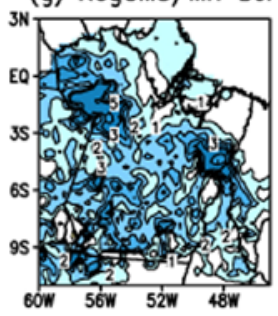

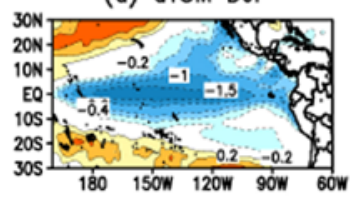

(b) OTSM MAM

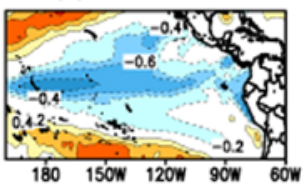

(d) RPCH MAM

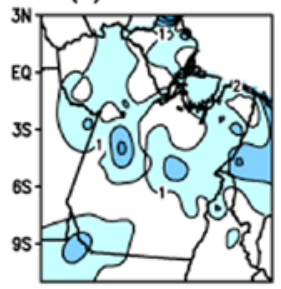

(f) RegCM3/Grell MAM

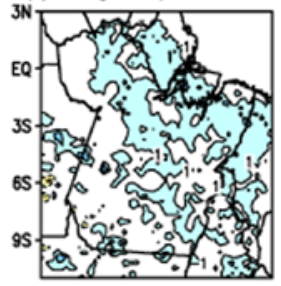

(h) RegCM3/MIT MAM

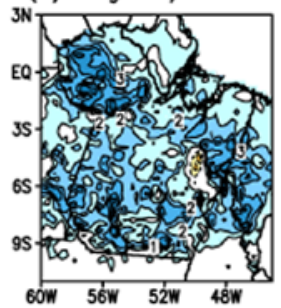

Figura 8 - Composição dos eventos La Niña para as anomalias de TSM $\left({ }^{\circ} \mathrm{C}\right)$ em (a) DJF e (b) MAM; Anomalias de precipitação (mm) observada pela RPCH em (c) DJF e (d) MAM e simulada pelo RegCM3/Grell em (e) DJF e (f) MAM e pelo RegCM3/MIT em (g) DJF e (h) MAM. águas oceânicas sobre o Oceano Pacífico tropical, indicado pela presença das anomalias positivas de TSM, durante DJF e MAM. O impacto do El Niño na variabilidade pluviométrica amazônica é bem conhecido. Inúmeros estudos anteriores demonstraram que as condições de aTSM mais quentes do que o normal deflagram mudanças significativas na circulação troposférica zonal da célula de Walker (Kousky et al., 1984; Pezzi e Cavalcanti, 2001; De Souza e Ambrizzi, 2002), inibindo a atividade convectiva da ZCIT e promovendo déficit significativo de precipitação na região (Coelho et al., 1999; De Souza et al., 2000). As Figuras 10c e 10d evidenciam a predominância de anomalias negativas de precipitação regional observada em grande parte da Amazônia oriental, exceto no sul e sudeste em DJF e no noroeste e sudeste em MAM, onde

\section{(a) oTSM DJF}
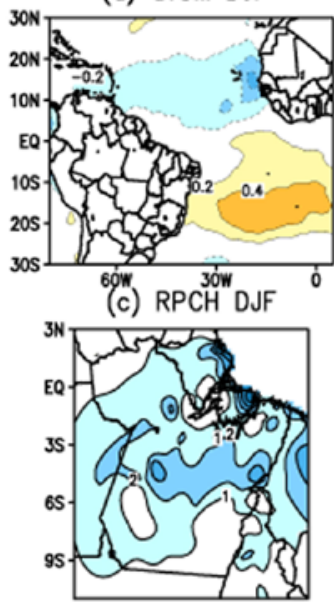

(e) RegCM3/Grell DJF

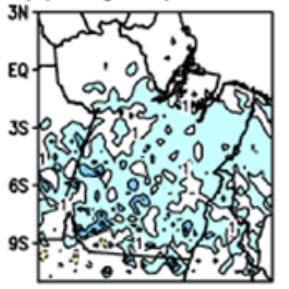

(g) RegCM3/MIT DJF

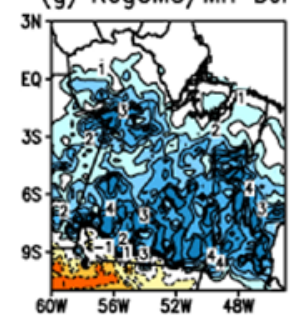

(b) aTSM MAM

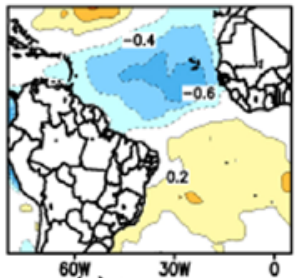

(d) RPCH MÁW

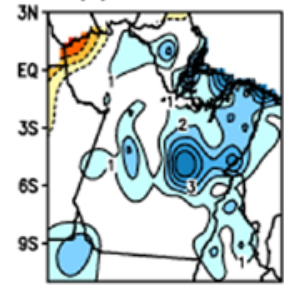

(f) $\operatorname{Reg} C M 3 /$ Grell MAM

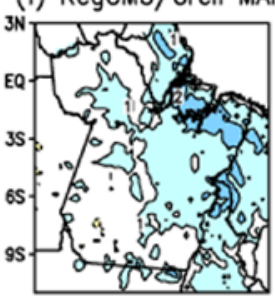

(h) RegCM3/MIT MAM

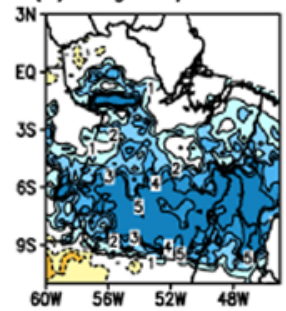

Figura 9 - Idem a Figura 8, porém para a composição dos eventos com gradiente de aTSM apontando para a bacia do Atlântico tropical sul. 
observam-se condições normais. Em DJF, notam-se impactos mais significativos no oeste e centro do Pará e litoral do Amapá, enquanto que em MAM, tais anomalias mais fortes localizam-se na porção leste/nordeste do Pará e toda faixa leste do Amapá. Nestas condições climáticas desfavoráveis de eventos El Niño, o modelo RegCM3 obteve resultados bastante consistentes com os dados observacionais, no que se refere a simulação de anomalias negativas de precipitação dominando grande parte da Amazônia oriental. Embora a precipitação simulada usando o esquema Grell tenha subestimado a intensidade das anomalias, o modelo conseguiu captar o padrão espacial em DJF e MAM (Figuras 10e e 10f). Usando o esquema MIT, o modelo também simulou anomalias negativas, mas com intensidade muito abaixo das observações para as estações de DJF e MAM (Figuras 10g e $10 \mathrm{~h})$.
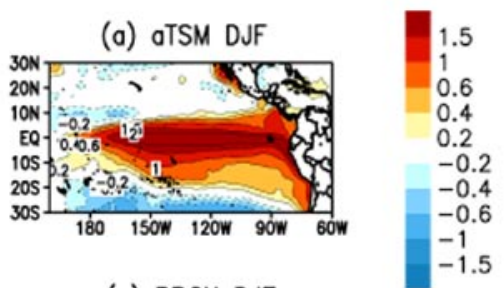

(b) ITSM MAM

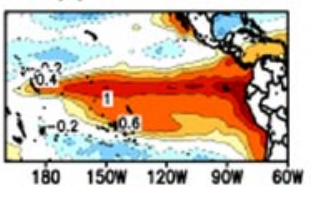

(d) RPCH MAM

(c) RPCH DJF

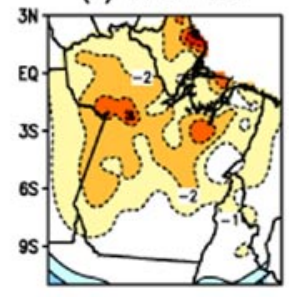

(e) RegCM3/Grell DJF

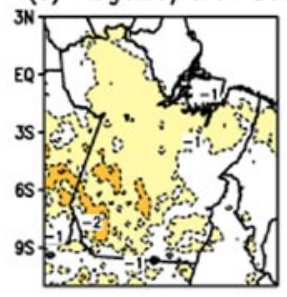

(g) RegCM3/MIT DJF

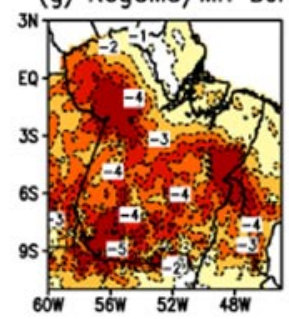

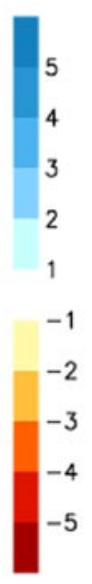

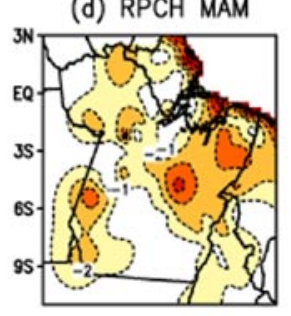

(f) RegCM3/Grell MAM

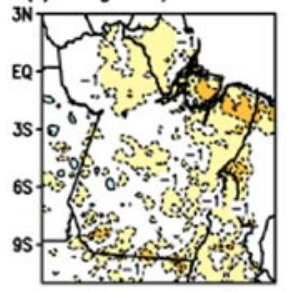

(h) RegCM3/MIT MAM

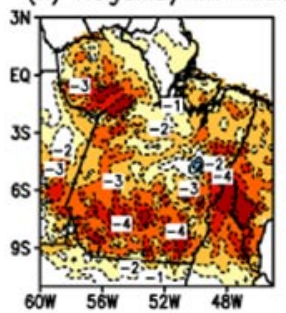

(a) aTSM DJF

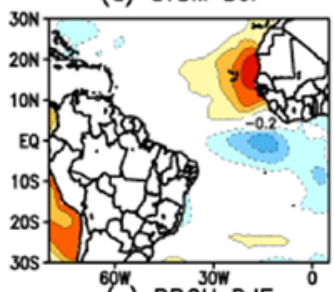

(c) RPCH' DJF

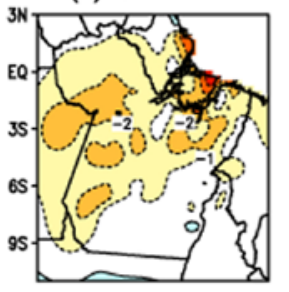

(e) RegCM3/Grell DJF

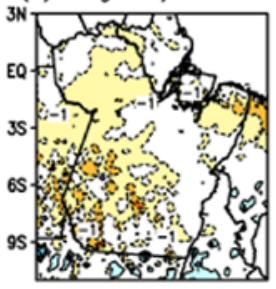

(g) RegCM3/MIT DJF

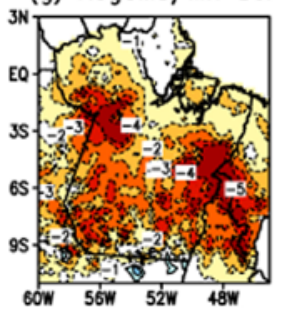

(b) ATSM MAM
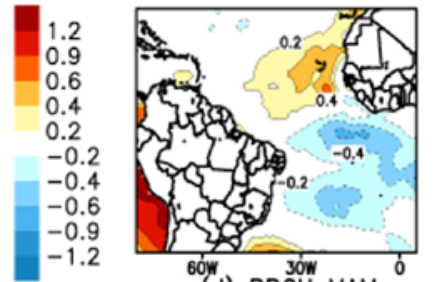

(d) RPCH MAM

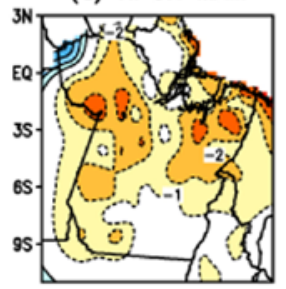

(f) RegCM3/Grell MAM

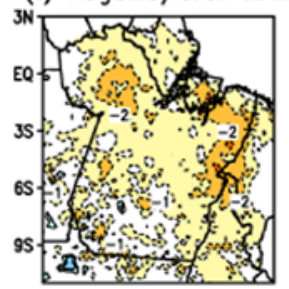

(h) RegCM3/MIT MAM

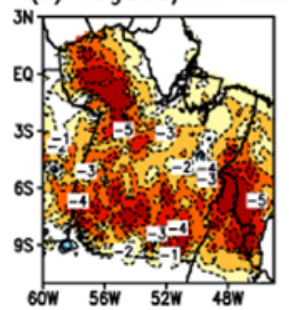

Figura 10 - Idem a Figura 8, porém para a composição dos eventos El Niño.

Figura 11 - Idem a Figura 8, porém para a composição dos eventos com gradiente de aTSM apontando para a bacia do Atlântico tropical norte. 
sudeste, e Amapá em DJF (Figura 11c) e em MAM, exceto no noroeste e sudeste do Pará e sul do Amapá (Figura 11d). Neste cenário climático desfavorável, novamente, o modelo RegCM3 conseguiu representar bem o padrão espacial abaixo do normal das anomalias pluviométricas, consistente com as observações. A precipitação simulada com o esquema Grell mostra anomalias negativas nos setores sudoeste, oeste centro, leste e nordeste do Pará e sul do Amapá durante as estações de DJF e MAM (Figuras 11e e 11f). A chuva prevista usando o esquema convectivo MIT, também conseguiu capturar o padrão espacial de precipitação abaixo do normal, porém mais uma vez a intensidade das anomalias ficou muito abaixo do padrão observado em ambos os períodos de DJF e MAM (Figuras 11g e 11h).

\section{DISCUSSÕES E CONCLUSÕES}

Apesar dos avanços nos estudos de modelagem obtidos nas últimas duas décadas, a representação numérica dos processos convectivos úmidos e a capacidade de simular o volume de precipitação regional e suas anomalias ainda é um desafio atual para a comunidade científica, particularmente para as regiões tropicais, a exemplo da Amazônia.

O presente trabalho apresenta uma contribuição aos estudos de modelagem climática com ênfase na variabilidade pluviométrica sazonal da Amazônia oriental, durante as estações de verão e outono (DJF e MAM). Baseado nos resultados das simulações climatológicas obtidas com o modelo RegCM3 para um período de 26 anos (1982/83 a 2007/08) e usando domínio em alta resolução espacial $(30 \mathrm{Km})$ e dois diferentes esquemas numéricos de convecção (Grell e MIT), foi investigado o desempenho do modelo em simular a distribuição regional de precipitação sazonal na Amazônia oriental, com referência a um novo conjunto de dados observacional compilado com informações provenientes de uma ampla rede integrada de estações pluviométricas (a precipitação RPCH; De Souza et al., 2007; De Souza et al., 2008). As análises qualitativa e quantitativa demonstraram que o RegCM3 apresenta erros sistemáticos, sobretudo aqueles relacionados com viés seco no Amapá e norte/nordeste do Pará usando ambos os esquemas Grell e MIT. Este resultado sugere claramente, que o modelo não consegue representar realisticamente as características básicas da ZCIT, principalmente sobre a área oceânica do Atlântico equatorial. As simulações usando o esquema MIT mostraram a presença de viés úmido no sudoeste/sul/sudeste do Pará. Estes resultados são similares aos encontrados em estudos anteriores que reportaram a predominância de subestimativa da chuva simulada na Amazônia tanto em modelos globais (Cavalcanti et al., 2002) como regionais (Misra et al. 2003; Seth e Rojas, 2003; Fernandez et al., 2003; Sun et al., 2006). Portanto, mesmo reduzindo-se o domínio horizontal das simulações $(30 \mathrm{Km}$, no caso do presente trabalho), continuam os erros sistemáticos na simulação de precipitação sobre a Amazônia. A investigação dos aspectos dinâmicos do porque o modelo apresenta tais erros, foge ao escopo do presente trabalho. Entretanto, encontra-se em andamento, um estudo sobre os padrões dinâmicos da circulação atmosférica na região da ZCIT, testes de modificação dos esquemas numéricos do modelo, bem como o uso de técnicas de ensemble e outros métodos estatísticos, com a finalidade de melhorar as simulações do RegCM3 e, assim, contribuir para o avanço da modelagem climática regional na Amazônia.

Adicionalmente, também foi investigado o desempenho do RegCM3 em reproduzir os padrões espaciais anômalos de precipitação sazonal em associação aos episódios ENOS e às fases do gradiente térmico sobre o Atlântico intertropical. As composições para os cenários considerados desfavoráveis, associados às condições de El Niño sobre o Pacífico e também às condições de gradiente de aTSM para o Atlântico tropical norte, demonstraram que o RegCM3 conseguiu representar realisticamente muito bem o padrão espacial de anomalias negativas de precipitação em grande parte da Amazônia oriental, consistente com as observações regionais documentadas pela precipitação RPCH. Da mesma forma, as composições dos cenários favoráveis, relacionados à ocorrência de La Niña no Pacífico e da fase do gradiente de aTSM para o Atlântico tropical sul, evidenciaram anomalias positivas de precipitação simulada configurando-se espacialmente na maior parte da Amazônia oriental, em conformidade com os dados observacionais. Tais padrões anômalos foram melhores sumulados usando Grell do que o MIT. Assim sendo, embora haja o problema de subestimativa da chuva simulada pelo RegCM3, o mesmo mostrou-se capaz de reproduzir os principais padrões espaciais anômalos da precipitação regional, o que implica sua viabilidade de utilização nas tarefas operacionais de monitoramento e previsão climática sazonal em escala regional. Portanto, os resultados obtidos demonstraram que o modelo RegCM3 tem potencial para investigar a variabilidade climática regional na Amazônia e fornecer valor agregado na geração de informações e previsões climáticas efetivamente úteis à comunidade amazônica.

\section{AGRADECIMENTOS}

À FINEP/MCT pelo financiamento do projeto RPCH (convênio 3641/06). Ao CNPq (processos 305390/2007-4 e 570113/2008-3), REDE CELPA e FAPESPA pelo apoio à pesquisa. À equipe do ITCP pela disponibilidade do código fonte do RegCM3 e a Dra. Rosmeri Rocha e Dr. J. Pablo Fernandez pelo apoio na configuração inicial do modelo na UFPA. Às instituições que mantém a árdua tarefa de coleta e manutenção da rede meteorológica observacional, matéria 
prima das pesquisas climatológicas, a saber: INMET, SEMA, ANA, CPRM, ELETRONORTE, EMBRAPA, SIPAM, CPTEC, entre outras. Os autores também agradecem os dois revisores da RBMet, cujas sugestões melhoraram substancialmente a apresentação deste trabalho.

\section{REFERENCIAS}

Adler, R.F. et al. The version 2 Global Precipitation Climatology Project(GPCP) monthly precipitation analysis (1979-present). Journal of Hydrometeorology, v. 4, p. 1147-1167, 2003.

Ambrizzi, T.; De Souza, E.B.; Pulwarty, R.S. The Hadley and Walker regional circulations and associated ENSO impacts on the South American seasonal rainfall.. In: Henry F. Diaz; Raymond S. Bradley. (Org.). The Hadley Circulation: Present, Past and Future. 1 Ed, Netherlands: Kluwer Academic Publishers, 2004. p. 203-235.

Carvalho, L.M.V.; Jones, C.; Liebmann, B. The South Atlantic Convergence Zone: intensity, form, persistence, and relationships with intraseasonal to interannual activity and extreme rainfall. Journal of Climate, v. 17, p. 88-108, 2004.

Cavalcanti, I.F.A. et al. Global climatological features in a simulation using the CPTEC-COLA AGCM. Journal of Climate, v. 15, n. 21, p. 2965-2988, 2002.

Chou, S.C. et al. Validation of the coupled Eta/SSiB model over South America. Journal of Geophysical Research, v. 107, n. D20, p. 8088, 2002.

Coelho, C.A.S. et al. Estudo climatológico sazonal da precipitação sobre o Brasil em episódios extremos da Oscilação Sul. Revista Brasileira de Meteorologia, v. 14, n. 1, p. 49-65, 1999.

Cuadra, S.V.; Rocha, R.P. Simulação numérica do clima de verão sobre o Brasil e sua variabilidade. Revista Brasileira de Meteorologia, v. 21, n. 2, p. 271-282, 2006.

De Souza, E.B.; Alves, J.M.B., Nobre, P. Anomalias de precipitação nos setores norte e leste do Nordeste Brasileiro em associação aos eventos do Padrão de Dipolo observados sobre o Atlântico Tropical. Revista Brasileira de Meteorologia, v. 13, n. 2, p. 45-56, 1998.

De Souza, E.B.; Nobre, P. Uma revisão sobre o Padrão de Dipolo no Oceano Atlântico tropical. Revista Brasileira de Meteorologia, v. 13, n. 1, p. 31-44, 1998.

De Souza, E.B. et al. On the influences of the El Niño, La Niña and Atlantic dipole pattern on the Amazonian rainfall during 1960-1998. Acta Amazonica, v. 30, n. 2, p. 305-318, 2000.

De Souza, E.B.; Ambrizzi, T. ENSO impacts on the South American rainfall during 1980s: Hadley and Walker circulation. Atmósfera, v. 15, p. 105-120, 2002.
De Souza, E.B.; Ambrizzi, T. Pentad precipitation climatology over Brazil and the associated atmospheric mechanisms. Climanálise, v. 1, p. 1-20, 2003. [Available online at http:// www.cptec.inpe.br/products/climanalise/artigos/artcien2. shtml].

De Souza, E.B. Principais mecanismos dinâmicos associados a variabilidade de precipitação diária sobre a Amazônia oriental durante a estação chuvosa. In: XIII Congresso Brasileiro de Meteorologia, 29/08 a 03/09/2004, FortalezaCE. Anais... Fortaleza: SBMET, 2004.

De Souza, E.B.; Kayano, M.T.; Ambrizzi, T. The regional precipitation over the eastern Amazon/northeast Brazil modulated by tropical Pacific and Atlantic SST anomalies on weekly timescale. Revista Brasileira de Meteorologia, v. 19, n. 2, p. 113-122, 2004.

De Souza, E.B.; Kayano, M.T.; Ambrizzi, T. Intraseasonal and submonthly variability over the eastern Amazon and Northeast Brazil during the autumn rainy season. Theoretical and Applied Climatology, v. 81, p. 177-191, 2005.

De Souza, E.B.; Rocha, E.J.P. Diurnal variations of rainfall in Bragança-PA (eastern Amazon) during rainy season: mean characteristics and extreme events. Revista Brasileira de Meteorologia, v. 21, n. 3a , p. 142-152, 2006.

De Souza, E.B.; et al. Rede Estadual de Previsão Climática e Hidrometeorológica do Pará - RPCH. Boletim da Sociedade Brasileira de Meteorologia, v. 31, p. 6-13, 2007.

De Souza, E.B. et al. Análise e previsão climática regional da Amazônia oriental: contribuições do projeto RPCH. In: XV Congresso Brasileiro de Meteorologia, 2008, São Paulo-SP. Anais... São Paulo: SBMET, 2008.

Dickinson, R.E.; Henderson-Sellers, A.; Kennedy, P.J. Biosphere-Atmosphere Transfer Scheme (BATS) version $1 \mathrm{E}$ as coupled to the NCAR Community Climate Model. NCAR Techical Report. TN-387+STR, NCAR, Boulder, Colorado, p. 72, 1993.

Dickinson, R.E. et al. A regional climate model for the western United States. Climate Change, v. 15, p. 383-422, 1989.

Druyan, L.M.; Fulakeza, M.; Lonergan, P. Dynamic downscaling of seasonal climate predictions over Brazil. Journal of Climate, v. 15, p. 3411-3426, 2002.

Emanuel, K.A.; Zivkovic-Rothman, M. Development and evaluation of a convection scheme for use in climate models. Journal of the Atmospheric Sciences, v. 56, p. 1766-1782, 1999.

Fernandez, J.P.R.; Franchito, S.H.; Rao, V.B. Simulation of the summer circulation over South America by two regional climate models. Part I: Mean climatology. Theoretical and Applied Climatology, v. 86, p. 247-260, 2006.

Figueroa, S.N.; Nobre, C.A. Precipitation distribution over central and western tropical South America. Climanálise, v. 5, p. $36-45,1990$. 
Giorgi, F.; Bates, G.T. The climatological skill of a regional climate model over complex terrain. Monthly Weather Review, v. 117, p. 2325-2347, 1989.

Giorgi, F.; Mearns, L.O. Introduction to special section: regional climate modeling revisited. Journal of Geophysical Research, v. 104, p. 6335-6352, 1999.

Giorgi, F.; Marinucci, M.R.; Bates, G.T. Development of a second-generation regional climate model (RegCM2). Part I: boundary-layer and radiative transfer processes. Monthly Weather Review, v. 121, p. 2794-2813, 1993 a.

Giorgi, F. et al. Development of a second-generation regional climate model (RegCM2). Part II: convective processes and assimilation of lateral boundary conditions. Monthly Weather Review, v. 121, p. 2814-2832, 1993 b.

Grell, G.A. Prognostic evaluation of assumptions used by cumulus parameterizations. Monthly Weather Review, v. 121, p. 764-787, 1993.

Holtslag, A.A.M.; De Bruijn, E.I.F.; Pan, H.L. A high resolution air mass transformation model for short-range weather forecasting. Monthly Weather Review, v. 118, p. 1561$1575,1990$.

Kalnay, E. et al. NCEP/NCAR 40-year Reanalysis project. Bulletin of the American Meteorological Society, v. 77, p. 437-471, 1996.

Kiehl, J.T. et al. Description of the NCAR Community Climate Model (CCM3). Boulder, Colorado: NCAR Technical Note, NCAR/TN-420+STR, 152 pp., 1996.

Kousky, V.E.; Cavalcanti, I.F.A.; Kayano, M.T. A review of the Southern Oscillation: oceanic-atmospheric circulation changes and related rainfall anomalies. Tellus, v. 36A, p. 490-504, 1984.

Marengo, J.A. et al. Onset and end of the rainy season in the Brazilian Amazon basin. Journal of Climate, v. 14, p. 833852, 2001.

Misra, V.; Dirmeyer, A.P.; Kirtman, B.P. Dynamic downscaling of seasonal simulation over South America. Journal of Climate, v.16, p. 103-117, 2003.

Nobre, P.; Moura, A.D.; Sun, L. Dynamical downscaling of seasonal climate prediction over Nordeste Brazil with ECHAM3 and NCEP's regional spectral model at IRI.
Bulletin of the American Meteorological Society, v. 82, p. 2787-2796, 2001.

Nobre, P.; Shukla, J. Variations of SST, wind stress and rainfall over the tropical Atlantic and South America. Journal of Climate, v. 9, p. 2464-2479, 1996.

Pal, J.S.; Small, E.E.; Eltahir, E.A.B. Simulation of regional scale water and energy budgets: influence of a new moist physics scheme within RegCM, Journal of Geophysical Research, v. 105, n. 29, p. 579-594, 2000.

Pal, J.S. et al. The ICTP RegCM3 and RegCNET: regional climate modeling for the developing World. Bulletin of the American Meteorological Society, v. 1, p. 1395-1409, 2007.

Pezzi, L.P.; Cavalcanti, I.F.A. The relative importance of ENSO and tropical Atlantic SST anomalies for seasonal precipitation over South America: a numerical study. Climate Dynamics, v. 17, p. 205-212, 2001.

Reynolds, R.W. et al. An improved in situ and satellite SST analysis for climate. Journal of Climate, v. 15, p. 1609-1625, 2002.

Rojas, M.; Seth, A. Simulation and sensitivity in a nested modeling system for South America. Part II: GCM boundary forcing. Journal of Climate, v. 16, p. 2454-2471, 2003.

Seth, A.; Rojas, M. Simulation and sensitivity in a nested modeling system for South America. Part I: reanalyses boundary forcing. Journal of Climate, v. 16, p. 2437-2453, 2003.

Seth, A. et al. RegCM3 regional climatologies for South America using reanalysis and ECHAM global model driving fields. Climate Dynamics, v. 28, p. 461-480, 2007.

Silva, V.B. et al. An improved gridded historical daily precipitation analysis for Brazil. Journal of Hydrometeorology, v. 8, p. 847-861, 2007.

Sun, L. et al. An operational dynamical downscaling prediction system from Nordeste Brazil and the 2002-04 real-time forecast evaluation. Journal of Climate, v. 19, p. 1990-2007, 2006.

Trenberth, K.E. The definition of El Niño. Bulletin of the American Meteorological Society, v. 78, p. 2771-2777, 1997. 